\title{
Pattern of inpatient referrals to a drug allergy unit in Kuwait
}

${ }^{1}$ Department of Microbiology, Faculty of Medicine, Kuwait University, Kuwait

${ }^{2}$ Drug Allergy Unit, Department of Allergy, Al-Rashed Allergy Center, Ministry of Health, Kuwait

\section{KEY WORDS}

drug hypersensitivity; inpatients;

Kuwait; referral and consultation

\section{Corresponding author}

Mona Al-Ahmad

Department of Microbiology

Faculty of Medicine, Kuwait University

P.O. Box 24923, Safat 13110, Kuwait

Phone: $+965-24636515$

Fax: $+965-25332719$

E-mail: Alahmadm@hsc.edu.kw

Doi

10.23822/EurAnnACI.1764-1489.18

\begin{abstract}
Summary
Introduction. There is no information regarding the pattern of inpatient referrals to drug allergy units in Kuwait. Objectives. The main goal of this study is to clarify the pattern of inpatient referrals to a drug allergy unit in terms of incidence, drugs implicated and allergy evaluation outcomes in comparison with studies in other countries. Patients and Methods. A retrospective chart review of inpatient drug allergy consultations at Al-Rashed Allergy Center over a 3-year period was performed. Results. A total of 51 patients were referred for drug allergy consultations, with an estimated incidence of reported drug allergy among inpatients of $0.008 \%$. There is an increasing trend of referrals from public health centres located in proximity to Al-Rashed Allergy Center. Beta-lactams, contrast media, and general anaesthetics were the most common drugs leading to referrals. In total, 30\% of patients were diagnosed with an allergy to the offending drug after a full allergy evaluation. Conclusion. Inpatient drug allergy referrals are highly underreported in Kuwait.
\end{abstract}

\section{Introduction}

There are few studies regarding inpatient consultations for allergy and immunology (1-3), and data are scarce when limited to inpatient drug allergy consultations. Adverse drug reactions (ADRs) have been reported in up to $10-20 \%$ of patients, with up to one-third of these reactions being allergic or pseudo-allergic in nature (3-5). Previous studies reported an incidence of drug allergic reactions among inpatients from $0.42 \%$ to $0.87 \%$ (3-5), with referral rates from $0.078 \%$ to $0.231 \%(3,4)$, but there are no data regarding Gulf-area countries, such as Kuwait. As the problem of drug allergies is growing worldwide, we sought to investigate referrals for drug allergies to clarify the pattern of inpatient consultations at our drug allergy unit in $\mathrm{Al}$ Rashed Allergy Center in terms of incidence, related drugs and allergy evaluation outcomes.

\section{Materials and methods}

Kuwait is divided into six governorates, which are served by six major general hospitals. Al-Rashed Allergy Center is located in the Sabah Hospital Area (in the capital area), and it serves all governorates in Kuwait.

Drug hypersensitivity reactions from all hospitals in Kuwait are referred to our center. This is a retrospective, descriptive study looking at all records from our referrals for inpatient drug allergies. Anaphylaxis has been defined as a severe, life-threatening generalized or systemic hypersensitivity reaction (6). Patients were managed following EAACI guidelines in the case of betalactams $(7,8)$, RCM (9) and anaesthesia (10). Skin test concentration were obtained from EAACI guidelines (11) and alternatively from AAAAI practice parameter (12) for the cases not included in EAACI guidelines. 
The data were collected for a 3-year period from patients referred to our center, from March 2010 to February 2013, and were reviewed for demographics, drugs implicated and allergy evaluation procedures and outcomes. Epidemiologic data were obtained from January 2011 to December 2013 from the Kuwait Ministry of Health (MOH) Statistics. Ethical approval was obtained from the institutional ethics committee (13-15). Clearance of the study protocol was obtained from the $\mathrm{MOH}$ Standing Committee for the Coordination of Health and Medical Research.

The data were coded, entered and analysed using SPSS version 20 software for Windows (IBM, Armonk, NY, USA).

\section{Results}

The study included 51 patients and a total of 53 drug consultations. The mean age was 41.69 years, with a range of 6 to 87 years, including 41 females and 10 males.

A total of fifteen referrals were to evaluate allergy to beta-lactams, nine to contrast media, six to anaesthesia, five to antituberculosis drugs, six to NSAIDs, two to carbamazepine, two to aminoglycosides and two to quinolones. Among the remaining six referrals, the offending drugs were protamine, allopurinol, clarithromycin, Vitamin D, hydrocortisone, and local antiseptics.

Unfortunately, eight consultations regarding beta-lactams and one each regarding antituberculosis drugs, quinolones and contrast

Table 1 - Reactions confirmed by the drug allergy evaluation.

\begin{tabular}{|c|c|c|c|c|c|c|}
\hline$\#$ & Age & Sex & Initial reaction & $\begin{array}{l}\text { Drug eliciting } \\
\text { response }\end{array}$ & $\begin{array}{l}\text { Diagnostic } \\
\text { evaluation }\end{array}$ & Comments \\
\hline 1 & 31 & $\mathrm{~F}$ & Anaphylaxis & General anesthesia & $\begin{array}{l}\text { Positive ST } \\
\text { Cisatracurium }\end{array}$ & $\begin{array}{l}\text { Alternative skin test negative drug was } \\
\text { used }\end{array}$ \\
\hline 2 & 26 & $\mathrm{~F}$ & Anaphylaxis & General anesthesia & $\begin{array}{l}\text { Positive ST rocuronium, } \\
\text { pancuronium }\end{array}$ & $\begin{array}{l}\text { Alternative skin test negative drug was } \\
\text { used }\end{array}$ \\
\hline 3 & 73 & M & Anaphylaxis & $\mathrm{RCM}$ & $\begin{array}{l}\text { Negative ST } \\
\text { Positive clinical history only }{ }^{1}\end{array}$ & Anaphylaxis despite premedication ${ }^{2}$ \\
\hline 4 & 59 & $\mathrm{~F}$ & Anaphylaxis & Carbamazepine & Positive clinical history only ${ }^{1}$ & $\begin{array}{l}\text { Alternative drug used, no further test } \\
\text { needed }\end{array}$ \\
\hline 5 & 67 & $\mathrm{~F}$ & Urticaria & Betalactams & Positive ST & Alternative antibiotic used \\
\hline 6 & 37 & M & Urticaria & Betalactams & Positive ST & Alternative antibiotic used \\
\hline 7 & 63 & $\mathrm{~F}$ & $\begin{array}{l}\text { Urticaria } \\
\text { Angioedema }\end{array}$ & Hydrocortisone & Positive ST & Challenge negative for dexamethasone \\
\hline 8 & 65 & $\mathrm{~F}$ & Urticaria & NSAIDs & Positive challenge & $\begin{array}{l}\text { Reaction during desensitization. sPatient } \\
\text { tolerated ASA } 81 \mathrm{mg}\end{array}$ \\
\hline 9 & 59 & M & Maculopapular & Allopurinol & Positive patch test & Unsuccessful desensitization \\
\hline 10 & 52 & $\mathrm{~F}$ & Maculopapular & Antituberculosis & $\begin{array}{l}\text { Positive patch test } \\
\text { isoniazid, rifampicin }\end{array}$ & Alternative antibiotic used \\
\hline 11 & 70 & $\mathrm{~F}$ & Maculopapular & Antituberculosis & $\begin{array}{l}\text { Positive clinical history } \\
\text { only }^{1}\end{array}$ & $\begin{array}{l}\text { Negative culture for TBC, so no further } \\
\text { test needed }\end{array}$ \\
\hline 12 & 56 & $\mathrm{~F}$ & Maculopapular & RCM & $\begin{array}{l}\text { Negative ST } \\
\text { Positive clinical history only }\end{array}$ & Maculopapular rash despite premedication ${ }^{2}$ \\
\hline 13 & 23 & $\mathrm{~F}$ & DRESS & Carbamazepine & Positive clinical history only ${ }^{1}$ & Alternative drug used, no further test needed \\
\hline 14 & 11 & M & DRESS & Betalactams & Positive clinical history only ${ }^{1}$ & Alternative drug used, no further test needed \\
\hline 15 & 29 & $\mathrm{~F}$ & DRESS & Antituberculosis & Positive clinical history only ${ }^{1}$ & Alternative drug used, no further test needed \\
\hline 16 & 30 & $\mathrm{~F}$ & DRESS & Antituberculosis & Positive clinical history only ${ }^{1}$ & Alternative drug used, no further test needed \\
\hline
\end{tabular}

${ }^{1} \mathrm{~A}$ positive clinical history was present in all cases. However, "only" was highlighted if a positive clinical history was used by itself for diagnosis.

${ }^{2}$ Premedication indicated as per EAACI guidelines (3). 
media were lost to follow-up. Among the forty-two patients who completed allergy evaluations, ten were confirmed to have drug allergies after full allergy evaluations and diagnostic workups, whereas six patients (two to carbamazepine and one each to beta-lactams, antituberculosis drugs, radiocontrast media and hydrocortisone) were deemed positive from clinical history alone. The remaining twenty-six patients were negative for drug allergy after full evaluations. Consultation for two different drugs in a single patient was presented, once for beta-lactams and quinolones and once for aminoglycosides and quinolones. A total of five patients presented with anaphylactic reactions, including two patients with reactions to neuroblocking agents, one with a reaction to RCM, one with a reaction attributed to Vitamin D and one attributed to carbamazepine. A total of 16/53 (30\%) reactions were deemed positive for drug allergy evaluation and they are summarized in table $\mathbf{1}$.

There were increased numbers of referrals from the pulmonary department and Sabah Hospital, located in close proximity to Al-Rashed Allergy Center (table 2). In the Sabah area, we found an average of 161,949 admissions per year for 3932 beds in general hospitals and 56,009 admissions per year for 2653 beds in specialty hospitals. Given an average of 17 patients referred per year during our study period, the estimated incidence of drug allergy among inpatient referrals based on 2011-2013 total hospital admissions is hence reported as $0.008 \%$ (tables $\mathbf{2}$ and $\mathbf{3}$ ).

\section{Discussion}

The pattern of inpatient referrals has significant variability among different studies, with beta-lactams as the most fre- quently implicated group of drugs for referrals, followed by sulphonamides and antiepileptic drugs $(5,16)$. In our study, the leading referred drugs for evaluation were beta-lactams, contrast media, and general anaesthetics.

We had an increased number of consultation for female patients, which is similar to other studies (2-5). One patient presented anaphylaxis immediately after carbamazepine intake, but skin testing other than patch is not standardized, and a confirmatory diagnostic work-up was not performed due to the availability of alternative medication. We decided to perform desensitization to allopurinol due to the non-severe nature of the previous reaction and the non available alternative (17), a previously published protocol (18) proved unsuccessful for this patient, due to continue flares of maculopapular rash. In $37 / 53(70 \%)$ reactions the patients were allowed to continue the offending medication as inpatient, and in 16/53 (30\%) of cases the patients were deemed as allergic to the offending drug. Among this 16 reactions, in $13(81 \%)$ a suitable alternative was found after cooperation between drug allergy unit and the refereeing consultant, and in $2(12 \%)$ cases who reacted to RCM, either desensitization or increased premedication was recommended for a safe administration of the drug on future exposures. This data supports the potential benefit of increasing the number of referrals to drug allergy units.

The increased referrals for antituberculosis drugs may be explained by close collaboration with and physical proximity to the pulmonary department (table 3). We also observed an increased number of consultations from hospitals located in our

Table 2 - Number of inpatient admissions and consultations among different specialty hospitals in Kuwait.

\begin{tabular}{lcccccc}
\hline $\begin{array}{l}\text { Specialty } \\
\text { Hospital }\end{array}$ & \multicolumn{2}{c}{ Admissions per year } & & $\begin{array}{l}\text { Referrals } \\
\text { (3 years) }\end{array}$ & $\begin{array}{l}\text { Referrals per 100 } \\
\text { admissions / year }\end{array}$ \\
\hline & $\mathbf{2 0 1 1}(\mathbf{1})$ & $\mathbf{2 0 1 2}(\mathbf{2})$ & $\mathbf{2 0 1 3} \mathbf{( 3 )}$ & Mean & & \\
\hline Allergy Center & 538 & 320 & 335 & 398 & 7 & 0.396 \\
\hline Chest Diseases & 7520 & 7733 & 7723 & 7659 & 7 & 0.030 \\
\hline Neurology & 12118 & 12087 & 12267 & 12157 & 4 & 0.011 \\
\hline Kuwait Cancer Center & 3339 & 3506 & 3423 & 3423 & 2 & 0.020 \\
\hline Psychiatry & 3936 & 3748 & 3525 & 3736 & 2 & 0.018 \\
\hline Orthopaedics/Trauma & 5606 & 5531 & 5642 & 5593 & 2 & 0.012 \\
\hline Other Specialized $^{2}$ & 23144 & 22921 & 23065 & 23043 & 0 & 0.000 \\
\hline Total & 56201 & 55846 & 55980 & 56009 & 24 & 0.014 \\
\hline
\end{tabular}

${ }^{1}$ Data from 2011-13

${ }^{2}$ Infectious Diseases, Maternity and Rehabilitation

1. Department of health information and medical reports Moh, State of Kuwait. Health, Kuwait 2011. Kuwait2011.

2. Department of health information and medical reports Moh, State of Kuwait. Title: Health, Kuwait 2012. Kuwait2012.

3. Department of health information and medical reports Moh, State of Kuwait: Health, Kuwait 2013; 2013. 
Table 3 - Number of inpatient admissions and consultations among different General hospitals in Kuwait.

\begin{tabular}{lccccccc}
\hline $\begin{array}{l}\text { General } \\
\text { Hospitals }\end{array}$ & \multicolumn{2}{c}{ Admissions } & & $\begin{array}{c}\text { Referrals } \\
\text { (3 years) }\end{array}$ & $\begin{array}{c}\text { Average referral } \\
\text { per 100 admission } \\
\text { In 1 year }\end{array}$ & $\begin{array}{c}\text { Distance } \\
(\mathbf{K m})^{\mathbf{2}}\end{array}$ \\
\hline Amiri & $\mathbf{2 0 1 1}(\mathbf{1})$ & $\mathbf{2 0 1 2}(\mathbf{2})$ & $\mathbf{2 0 1 3}(\mathbf{3})$ & Average & & & \\
\hline Sabah & 16537 & 16406 & 16859 & 16601 & $12^{1}$ & 0.024 & 12 \\
\hline Mubarak & 18619 & 16179 & 16565 & 17121 & 8 & 0.016 & - \\
\hline Adan & 20243 & 20681 & 21148 & 20691 & 3 & 0.005 & 15 \\
\hline Farwaniya & 35129 & 37113 & 39020 & 37087 & 3 & 0.003 & 37 \\
\hline Jahra & 34587 & 34439 & 35921 & 34982 & 1 & 0.001 & 15 \\
\hline Total & 160457 & 160227 & 165163 & 161949 & 27 & 0.000 & 27 \\
\hline
\end{tabular}

19 in 2013

${ }^{2}$ Distances from different hospitals in Kuwait to Sabah area (Al-Rashed allergy center).

1. Department of health information and medical reports Moh, State of Kuwait. Health Kuwait 2011; 2011.

2. Department of health information and medical reports Moh, State of Kuwait. Health Kuwait 2012; 2012.

3. Department of health information and medical reports Moh, State of Kuwait: Health, Kuwait 2013; 2013.

medical area (Sabah), as well as a decreased number of consultations from distant areas (table 1). Interestingly, five out of six salicylate referrals occurred in the final year of the study, and all were requests for aspirin challenge / desensitization by cardiology intensive care units prior to percutaneous intervention. This emphasizes the importance of other departments having knowledge of the services offered by drug allergy units.

In an 18-month-long study in the USA (4) with 36,653 hospitalizations, a $2 \%$ incidence of ADR was observed, and antihistamines were administered to $32.7 \%$ of this group, with an incidence of $0.65 \%$ of suspected allergic reactions per hospitalization. Interestingly, only $12.6 \%$ of ADRs were reported by a staff physician, and the remaining were obtained via an electronic review of records. In a 2-year study in Singapore (3) covering 90,910 hospitalizations, a $0.42 \%$ estimated incidence of drug allergy was calculated after a random review of electronic records, with only a $0.23 \%$ incidence of reported drug allergy. In a study in Korea (5) with 55,432 admissions, a mandatory system of reporting drug hypersensitivity was introduced, and a $4.84 \%$ incidence of ADR was found, with only $18 \%$ identified as drug hypersensitivity reactions after allergist review, compared with a $0.5 \%$ incidence of ADR reported prior to the mandatory reporting system. Consultations for allergy and immunology were studied by Otto et al. (2) in a centre with 218 beds and 15,000 admissions / year, and they noted approximately 15.5 consultations / year for ADRs.

In this study, we calculated the incidence of drug allergy referrals as $0.008 \%$ among inpatients. This is a significantly lower estimate than those of previous studies in different countries, in which the incidence of drug allergic reactions among inpatients was calculated as $0.42 \%$ to $0.87 \%(3-5)$, with referral rates of $0.078 \%$ to $0.231 \%(3,4)$. However, despite the fact that the number of unreported drug allergic reactions among inpatients has not been examined in our study population, we suppose that this population has a low number of referrals compared with the real incidence of allergic reactions among inpatients, based on previous studies from other countries (3-5). Anaphylactic reactions to drugs are reported to be as high as 1.5 per 5000 patients (19), and they should be referred to the allergy department for further workup. The unexpected incidence of 1.66 referrals / year $(0.76$ per 100,000 inpatients) for anaphylactic reactions, may be explained by underreporting rather than by a low incidence of anaphylactic reactions. Despite we do not have data to support our hypothesis, we are aware that it might be a bias towards consultation of severe reactions while treating doctors usually manage milder reactions by themselves, usually simply avoiding the offending medication and using second-line therapies, even if they are less effective. In light of these data, we suppose that drug allergies among inpatients are underreported in Kuwait.

Drug desensitization allows the re-introduction of first-line medications in allergic patients. There were only six referrals for desensitization during the period of this study, and none of them were for chemotherapeutics, antibiotics or monoclonal antibodies. This was an interesting and rather unexpected finding, particularly given the wealth of evidence supporting good safety and efficacy profiles $(20,21)$.

The field of drug allergies relies almost entirely on referrals from physicians from other specialties and general practitioners. $\mathrm{Pa}-$ 
tients "labelled" as allergic to beta-lactams are more likely to be treated with broad-spectrum antibiotics, such as vancomycin or quinolones, leading to increased costs, antibiotic resistance, inpatient admission length-of-stay and overall mortality (22).

Our study has a number of limitations. The low number of referrals may be due to the recent establishment of the drug allergy unit in December 2009 and a lack of knowledge among physicians regarding its existence, as proven by the low number of referrals from distant governorates. A systematic review of files would have revealed the frequency of underreported drug allergy reactions in our study populations, but the lack of electronic records makes this task impossible for our staff.

In conclusion, this is the first study showing highly underreported number of referrals for inpatient drug allergy in a Gulf-area country, with a total of $0.008 \%$ compared to $0.42 \%$ to $0.87 \%$ in other studies, and these differences are increased among hospitals distant to our center. We are working to increase the awareness of allergy evaluations of ADRs to assist with providing better health services that meet the standard of care.

All authors contributed equally in the idea, design, data collection and analysis. All authors edited and approved the final version of the manuscript.

\section{References}

1. England RW, Ho TC, Napoli DC, Quinn JM. Inpatient consultation of allergy / immunology in a tertiary care setting. Ann Allergy Asthma Immunol. 2003;90(4):393-7.

2. Otto HF, England RW, Quinn JM. Inpatient allergy / immunology consultations in a tertiary care setting. Allergy Asthma Proc. 2010;31(3):244-51.

3. Thong BY, Leong KP, Tang CY, Chng HH. Drug allergy in a general hospital: Results of a novel prospective inpatient reporting system. Ann Allergy Asthma Immunol. 2003;90(3):342-7.

4. Classen DC, Pestotnik SL, Evans RS, Burke JP. Computerized surveillance of adverse drug events in hospital patients. JAMA. 1991;266(20):2847-51.

5. Park CS, Kim TB, Kim SL, Kim JY, Yang KA, Bae YJ, et al. The use of an electronic medical record system for mandatory reporting of drug hypersensitivity reactions has been shown to improve the management of patients in the university hospital in Korea. Pharmacoepidemiol Drug Saf. 2008;17(9):919-25.

6. Johansson SG, Bieber T, Dahl R, Friedmann PS, Lanier BQ, Lockey $\mathrm{RF}$, et al. Revised nomenclature for allergy for global use: Report of the Nomenclature Review Committee of the World Allergy Organization, October 2003. J Allergy Clin Immunol. 2004;113(5):832-6.

7. Blanca M, Romano A, Torres MJ, Fernandez J, Mayorga C, Rodriguez J, et al. Update on the evaluation of hypersensitivity reactions to betalactams. Allergy. 2009;64(2):183-93.
8. Romano A, Blanca M, Torres MJ, Bircher A, Aberer W, Brockow $\mathrm{K}$, et al. Diagnosis of nonimmediate reactions to beta-lactam antibiotics. Allergy. 2004;59(11):1153-60.

9. Brockow K, Christiansen C, Kanny G, Clement O, Barbaud A, Bircher A, et al. Management of hypersensitivity reactions to iodinated contrast media. Allergy. 2005;60(2):150-8.

10. Mertes PM, Malinovsky JM, Jouffroy L, Working Group of the S, Sfa, Aberer W, et al. Reducing the risk of anaphylaxis during anesthesia: 2011 updated guidelines for clinical practice. J Investig Allergol Clin Immunol. 2011;21(6):442-53.

11. Brockow K, Garvey LH, Aberer W, Atanaskovic-Markovic M, Barbaud A, Bilo MB, et al. Skin test concentrations for systemically administered drugs - an ENDA/EAACI Drug Allergy Interest Group position paper. Allergy. 2013;68(6):702-12.

12. Joint Task Force on Practice P, American Academy of Allergy A, Immunology, American College of Allergy A, Immunology, Joint Council of Allergy A, et al. Drug allergy: an updated practice parameter. Ann Allergy Asthma Immunol. 2010;105(4):259-73.

13. Department of health information and medical reports Moh, State of Kuwait. Health Kuwait 2011; 2011.

14. Department of health information and medical reports Moh, State of Kuwait. Health Kuwait 2012; 2012.

15. Department of health information and medical reports Moh, State of Kuwait: Health, kuwait 2013; 2013.

16. Demoly P VM, Gomes ER, Romano A. Epidemiology and causes of drug hypersensitivity. In: WJ. P, editor. Drug Hypersensitivity: Karger; 2007. p. 18-31.

17. Scherer K, Brockow K, Aberer W, Gooi JH, Demoly P, Romano A, et al. Desensitization in delayed drug hypersensitivity reactions -- an EAACI position paper of the Drug Allergy Interest Group. Allergy. 2013;68(7):844-52.

18. Fam AG, Dunne SM, Iazzetta J, Paton TW. Efficacy and safety of desensitization to allopurinol following cutaneous reactions. Arthritis Rheum. 2001;44(1):231-8.

19. Tejedor Alonso MA, Moro MM, Hernandez JE, Mugica Garcia MV, Albelda CV, Ingelmo AR, et al. Incidence of anaphylaxis in hospitalized patients. Int Arch Allergy Immunol. 2011;156(2):212-20.

20. Castells MC, Tennant NM, Sloane DE, Hsu FI, Barrett NA, Hong DI, et al. Hypersensitivity reactions to chemotherapy: outcomes and safety of rapid desensitization in 413 cases. The Journal of allergy and clinical immunology. 2008;122(3):574-80.

21. Legere HJ, 3rd, Palis RI, Rodriguez Bouza T, Uluer AZ, Castells MC. A safe protocol for rapid desensitization in patients with cystic fibrosis and antibiotic hypersensitivity. Journal of cystic fibrosis : official journal of the European Cystic Fibrosis Society. 2009;8(6):418-24.

22. Macy E, Contreras R. Health care use and serious infection prevalence associated with penicillin "allergy" in hospitalized patients: A cohort study. The Journal of allergy and clinical immunology. 2014;133(3):790-6. 